\title{
Autologous Hematopoietic Stem Cell Transplantation for Multiple Myeloma in India
}

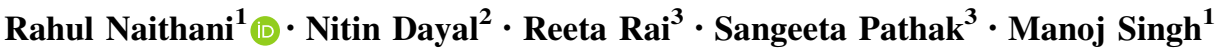

Received: 8 December 2017 / Accepted: 14 March 2018/Published online: 22 March 2018

(C) Indian Society of Hematology and Blood Transfusion 2018

To the Editor,

There is lack of data on multiple myeloma (MM) transplants from India [1]. In this regard, we read article by Malhotra et al. [2] with interest and will like to share our data.

Over last 5 years 60 autologous hematopoietic stem cell transplant (HSCT) were performed for 55 patients (21 females) with MM. Five patients underwent tandem autologous BMT and were excluded. Data on remaining 50 patients are presented. Stem cells were stored in blood bank refrigerator at $4{ }^{\circ} \mathrm{C}$. CD34 cell enumeration was performed using ISHAGE protocol [3].

Transplant parameters are outlined in Table 1. Median age was 56 years (36-68 years). Thirty-one patients were in complete remission (CR), 3 had very good partial remission (VGPR), 15 had partial remission (PR) and 1 had active disease at the time of transplant. Peripheral blood stem cell apheresis were performed using Hemonetics MCS + or Cobe spectra apheresis machine using double lumen central venous catheter. Melphalan $140 \mathrm{mg} /$ $\mathrm{m}^{2}$ was used in 21 patients ( 15 due to renal impairment and 6 due to comorbidities or overall clinical state).

Median dose of HSCs infused was $2.65 \times 10^{6} / \mathrm{kg}$. Eight patients had CD 34 dose between 1.5 and $2 \times 10^{6} / \mathrm{kg}$. Grade III or IV mucositis was seen in $78 \%$ patients. All 50

Rahul Naithani

dr_rahul6@hotmail.com

1 Division of Hematology and Bone Marrow Transplantation, Max Superspeciality Hospital, New Delhi, India

2 Department of Lab Medicines, Max Superspeciality Hospital, New Delhi, India

3 Department of Transfusion Medicine, Max Superspeciality Hospital, New Delhi, India patients developed febrile neutropenia. Cause for fever could be documented clinically, radiologically or microbiologically in 24 (48\%) patients (Table 1). Fifteen patients developed gram negative infections. Four patients developed gram positive infection (3 MRSA and 1 staphylococcal epidermidis) during febrile episode. One patient each developed CMV reactivation after engraftment, H1N1 infection with respiratory distress and Herpes esophagitis. All 3 patients survived. One patient developed cryptosporidium diarrhea. Day 30 treatment related mortality (TRM) was nil. One dialysis dependent patient died on day 37 after primary graft failure taking our Day 100 TRM to $2 \%$. His blood culture grew methicillin resistant staphylococcus aureus, E coli and Providencia rettgeri.

In 4 patients, response after transplant was not available because 1 had TRM and 3 progressed (1 CR and 2 PR at the time of HSCT) between day 30 and 100 days one progressed to plasma cell leukemia, one had CNS progression within 6 weeks of BMT and died. Three other patients relapsed at various time points and succumbed to that. Remission status after transplant were: patient with active disease at the time of transplant attained PR; all 3 patients with VGPR attained CR. Out of 15 patients with PR-6 attained CR, 3 VGPR, 3 PR and 3 progressed. Twelve patients relapsed of which 8 patients are on active therapy at this time.

The median follow-up time from transplant was 1.4 year (4-71 months). Age $<45$ years or more and disease status at the time of transplantation did not affect survival. Overall survival of entire cohort was $86 \%$.

It has been shown that ASCT improves quality of life and is cost effective in India compared to chemotherapy if performed early in disease course [4]. In India, patients often present to transplant centers late and have often received multiple lines of chemotherapies by then. This 
Table 1 Transplant parameters of study population

\begin{tabular}{|c|c|}
\hline Salvage chemotherapy before HSCT & $\mathrm{N}=13$ \\
\hline Bortezomib/dexamethasone & 2 \\
\hline $\mathrm{ABCD}$ & 3 \\
\hline CTD & 2 \\
\hline $\mathrm{BCD}$ & 1 \\
\hline DT-PACE & 2 \\
\hline VAD & 2 \\
\hline Daratumumab & 1 \\
\hline Stem cell mobilisation & $\mathrm{N}=50$ \\
\hline G-CSF & 34 \\
\hline Cyclophosphamide + G-CSF & 8 \\
\hline Plerixafor + G-CSF & 5 \\
\hline Plerixafor + G-CSF + cyclophosphamide & 1 \\
\hline $\mathrm{VAD}$ & 1 \\
\hline DTPACE & 1 \\
\hline CD 34 dose infused $\left(\times 10^{6} / \mathrm{kg}\right)$ & $2.65(1.52-17)^{\mathrm{a}}$ \\
\hline \multicolumn{2}{|l|}{ Melphalan dose } \\
\hline $140 \mathrm{mg} / \mathrm{m}^{2}$ & 21 \\
\hline $200 \mathrm{mg} / \mathrm{m}^{2}$ & 29 \\
\hline Engraftment & Median (range) \\
\hline Neutrophils & 11 (9-14) days \\
\hline Platelets & 11 (9-32) days \\
\hline Infections & $\mathrm{N}=50$ \\
\hline Febrile neutropenia & 50 \\
\hline Fever of unknown origin & 26 \\
\hline Microbiologically documented infection & 18 \\
\hline Clinically documented infection & 2 \\
\hline Radiological (pneumonia) & 1 \\
\hline Viral & 3 \\
\hline Fever & 4 (1-16) days \\
\hline Mucositis & $\mathrm{N}=47$ \\
\hline Grade 2 & 8 \\
\hline Grade 3 & 23 \\
\hline Grade 4 & 16 \\
\hline Death & $\mathrm{N}=7$ \\
\hline Day 30 TRM & 0 \\
\hline Day 100 TRM & $1(2 \%)$ \\
\hline Progressive disease & 6 \\
\hline Hospital stay & 19 (14-61) days \\
\hline
\end{tabular}

NA, not available; ABCD, liposomal doxorubicin, bortezomib, cyclophosphamide, dexamethasone; BCD, bortezomib, cyclophosphamide, dexamethasone; CTD, cyclophosphamide, thalidomide, dexamethasone; VAD, vincristine, doxorubicin, dexamethasone; DTPACE, dexamethasone, thalidomide, cisplatin, doxorubicin, cyclophosphamide, etoposide; G-CSF, granulocyte colony stimulating factor; TRM, transplant related mortality

${ }^{\mathrm{a}} 8$ patients had stem cell dose between 1.5 and 2 million $/ \mathrm{kg}$ affects stem cell yield. We used plerixafor for 6 patients and stem cells could be harvested in all successfully. Kumar et al. [5] have shown success rates of $84 \%$ in patients earlier treated with lenalidomide. Gram negative infections continue to be major problem for transplant units as has been earlier documented [1,2]. Average transplant cost for multiple myeloma at our center is Rs. 6 lakhs.

Progression after transplant is a poor prognosis feature. Larger multicentric data and longer follow up would make us wiser in making appropriate treatment decisions.

\section{Compliance with Ethical Standards}

Conflict of interest The author declares that they have no conflict of interest.

Ethical Approval The study was approved by Institutes' Ethics Committee.

\section{References}

1. Kumar L, Boya RR, Pai R et al (2016) Autologous stem cell transplantation for multiple myeloma: long-term results. Natl Med J India 29(4):192-199

2. Malhotra P, Yanamandra U, Khadwal A et al (2017) Autologous stem cell transplantation for multiple myeloma: single centre experience from North India. Indian J Hematol Blood Transfus. https://doi.org/10.1007/s12288-017-0876-y

3. Naithani R, Dayal N, Dixit G (2017) Single versus dual platform analysis for hematopoietic stem cell enumeration using ISHAGE protocol. Indian J Hematol Blood Transfus 33(3):370-374

4. Prinja S, Kaur G, Malhotra P et al (2017) Cost-effectiveness of autologous stem cell treatment as compared to conventional chemotherapy for treatment of multiple myeloma in India. Indian J Hematol Blood Transfus 33(1):31-40

5. Kumar R, Kapoor R, Asthana B et al (2017) Single dose preemptive plerixafor for stem cell mobilization for ASCT after lenalidomide based therapy in multiple myeloma: impact in resource limited setting. Indian $\mathrm{J}$ Hematol Blood Transfus 33(4):463-469 